\title{
HYDATID CYST LIVER EXCISION: THE TWIN PROBLEMS OF ANAPHYLAXIS
} AND HYPERNATREMIA

\author{
Anand Rampure Vittal Rao', Vijay Narayanan S2, Santhosh C. Gudimani ${ }^{3}$
}

\section{HOW TO CITE THIS ARTICLE:}

Anand Rampure Vittal Rao, Vijay Narayanan S, Santhosh C. Gudimani. "Hydatid CYST Liver Excision: The Twin Problems of Anaphylaxis and Hypernatremia". Journal of Evolution of Medical and Dental Sciences 2015; Vol. 4, Issue 38, May 11; Page: 6675-6678, DOI: 10.14260/jemds/2015/966

ABSTRACT: Hydatid cyst infestation is most commonly encountered in liver. Though several procedures have been described in the treatment of hepatic echinococcal cysts ranging from simple puncture to liver resection, radical surgery (Total pericystectomy or partial hepatectomy) is indicated for liver cyst. Prevention of spillage into the peritoneal cavity and wound edges by injecting a scolicidal agent into the unopened cyst and walling off the operative field with sponges soaked in a scolicidal agent are the two most commonly employed measures. $20 \%$ hypertonic saline is one of the recommended scolicidal agent, but can be associated with hypernatremia. Anaphylaxis during hydatid cyst resection is one of the rare occurrences. We hereby describe the twin problem of Anaphylaxis intraoperatively and hypernatremia postoperatively and its management.

KEYWORDS: Hydatid cyst, scolicidal agent, 20\% hypertonic saline, anaphylaxis, hypernatremia.

INTRODUCTION: Hydatid cyst is the larval form of cestode tapeworm echinococcus granulosus.[1] Infestation by hydatid disease in humans most commonly occurs in the liver (55-70\%) followed by the lung (18-35\%).[2] Though several procedures have been described in the treatment of hepatic echinococcal cysts ranging from simple puncture to liver resection, radical surgery (total pericystectomy or partial hepatectomy) is indicated for liver cysts. Prevention of spillage into the peritoneal cavity and wound edges by injecting a scolicidal agent into the unopened cyst and walling off the operative field with sponges soaked in a scolicidal agent are the two most commonly employed measures. $10-30 \%$ saline, $3 \%$ hydrogen peroxide, $1.5 \%$ cetrimide $-0.15 \%$ chlorhexidine, 95\% ethyl alcohol, 10\% polyvinylpirrolidone-iodine [Betadine(R)] have all been used as scolicidal agents.[3]

We report a case of hydatid cyst liver resection, wherein we had to contemplate with the twin problems of anaphylaxis intraoperatively as well as deal with hypernatremia postoperatively.

CASE REPORT: A 47 years old male weighing $67 \mathrm{Kg}$ had been diagnosed with hydatid cyst infestation of the liver. He had the symptom of dull abdominal pain in the right upper quadrant with no history of any other systemic illness. His eosinophil count was $22 \%$ and ultrasound and CT Scan abdomen had clinched the diagnosis of a large cyst measuring 9X6X4.5 cm on left liver lobe. Liver function tests were within normal limits. He was planned for laparotomy and resection of the hydatid cyst. He was monitored intraoperatively with electrocardiography, Pulse oximetry, Oesophageal temperature, Invasive arterial line (Right Radial artery), Central Venous Pressure (CVP). Scolicidal agent chosen was $20 \%$ saline. Mops dipped in $20 \%$ saline were used on surgical field to avoid any scolicidal spillage and subsequent infestation (invitro studies have proven $20 \%$ saline to be scolicidal within 5 minutes).[3]

Patient was stable till the the time part of the liver with hydatid cyst was resected. Haemostasis was well achieved till then and there was no obvious excess blood loss. We noticed a 


\section{CASE REPORT}

sudden drop in blood pressures (BP) from 130/70 $\mathrm{mmHg}$ to around 70/40 $\mathrm{mm} \mathrm{Hg}$. We also noticed a drop in CVP from around $8 \mathrm{mmHg}$ to $3 \mathrm{mmHg}$. Rapid IV fluid infusion was instituted including hetastarch. Inspite of supplementing with adequate fluid, and boluses of ephedrine, BP remained on the lower side. Peak airway pressures also had increased from $16 \mathrm{mmHg}$ to $22 \mathrm{mmHg}$. On Auscultation, we could not hear any rhonchi, neither we noticed any cutaneous signs on the exposed areas. Arterial blood gas analysis (ABG) showed $\mathrm{PaO}_{2}$ of $120 \mathrm{mmHg}$ and $\mathrm{PaCO}_{2}$ of $52 \mathrm{~mm} \mathrm{Hg}$ for an $\mathrm{FiO}_{2}$ of $50 \%$ and sodium (Na) at $156 \mathrm{meq} / \mathrm{L}$. Considering Anaphylaxis as a possible cause, we administered inj Hydrocortisone $100 \mathrm{mg}$ iv bolus and also started adrenaline infusion at $0.02 \mathrm{mcg} / \mathrm{kg}$ /min. BP improved to around 100-120/50-60 mmHg.[4]

After the completion of the procedure, patient was shifted to Postoperative ICU and continued on Ventillatory support. His repeat ABG showed hypernatremia (Na-162 meq/L) and patient was drowsy. We started him on hypotonic saline of $0.45 \%$ alternating with $5 \%$ dextrose at $140 \mathrm{ml} / \mathrm{hr}$ with periodic monitoring of serum Na levels. Patients was extubated next day morning after his conscious level had improved and was responding well, with Na levels around $152 \mathrm{meq} / \mathrm{L}$ and BP had stabilised with adrenaline tapered and stopped. His Na levels came within normal limits 28 hrs post shifting to ICU.

DISCUSSION: Walling off the surgical field with laparotomy sponges or packs soaked in scolicidal agents is an effective and logical means of using scolicidal agents if the agent is chosen correct. Sponges work not only as a mechanical barrier but also as a chemical one. In the surgical management of this disease, neutralization of the parasite, evacuation of the cyst and the management of the residual cavity are the principal steps. Though many other scolicidal agents are available, each of them are associated with some of the possible complications. Ethyl alcohol is the scolicidal agent that is usually preferred for ultrasonic-guided percutaneous aspiration, injection and reaspiration (PAIR) of hydatid cysts. Unfortunately, it can cause caustic damage to the epithelium of communicating bile ducts leading to sclerosing cholangitis. ${ }^{[5]}$ Hydrogen peroxide has not gained wide acceptance because of low efficacy and complications. Betadine (R) is a disinfectant that can be used but can cause storage disease, renal shutdown, sterile peritonitis and sclerosing serositis. [6] Hypertonic saline and cetrimide have become the scolicidal agents of choice over the past years. Cetrimide is a very potent scolicidal agent even at very low concentrations that makes it the scolicidal agent of choice in the situations where it is hard to anticipate the volume of the cyst and adjust for dilution of the scolicidal agent. Although cetrimide is effective in very low concentrations, it is not devoid of complications. Metabolic acidosis and methemoglobinemia were reported due to cetrimide installation into hydatid cysts.[5]

In the surgery of hydatid cyst, the incidence of anaphylaxis was variable. The mechanism of these reactions is complex. In some cases, it is typically a hypersensitivity reaction type I associated with immunoglobulin $\mathrm{E}$ in response of a high plasma concentration of antigens ecchinococcus. Anaphylactic or anaphylactoid reactions may also be secondary to complement activation with liberation of anaphylatoxins.[4] Under anesthesia, cardiovascular signs such as hypotension, tachycardia, and arrhythmia predominate. Cutaneous symptoms, such as rash, flushing, and urticaria, are common in the neck, face, and especially on the anterior chest, but these signs are often hidden by surgical draping. Occurrence of bronchospasm is less frequent and less sensitive. Nevertheless, the diagnosis of anaphylaxis should be established by various immunologic immunofluorescence reactions and immunoelectrophoresis hemagglutination. ${ }^{[4]}$ 
In our center, these reactions were unavailable and not realized in our patient. For vasopressor, epinephrine is the first-line treatment in most guidelines on perioperative management of anaphylaxis. Glucocorticoids are often administered in acute phase of anaphylactic shock, although their effects are delayed several hours; a beneficial role has been suggested to prevent the recurrence of manifestations of anaphylaxis in the late phase.[7] Hydatid cyst surgery though is often simple, the occurrence of hemodynamic instability, apart from the bleeding and hypovolemia, should suggest the diagnosis of anaphylaxis and start the specific management.

Hypernatremia may have resulted from absorption of hypertonic saline through cysts walls and from exchange of both salt and water through the peritoneal membrane. The mechanism of hypernatremia after a hypertonic saline injection involves both a total body Na gain and a free water loss.[8] The relative water deficit (i.e., the amount of positive water balance required to return the serum $\mathrm{Na}$ concentration to $140 \mathrm{mmol} / \mathrm{L}$ ) was around 6 litres, as estimated by the formula: $0.6 \times$ lean body weight $(\mathrm{kg}) \times([$ current $\{\mathrm{Na}\} / 140]-1)$. Here we have used $0.45 \%$ hypotonic saline and $5 \%$ dextrose infusion @140ml/hr.

Acute hypernatremia leads to a rapid decrease in brain water content [9]. Dehydration of cerebral cells with brain shrinkage may result in intracranial vascular damage and subdural hematomas. [10] In response to hypernatremia, the brain undergoes adaptive responses to minimize osmotic shrinkage. Intracellular accumulation of osmoles tends to counteract brain water loss. However, this protective change exposes the patient to cerebral edema that may arise from failure of the osmoles to dissipate at the same rate as correction of hypernatremia. Hence, correction of hypernatremia over $24 \mathrm{hr}$ normally does not lead to cerebral edema. ${ }^{[9,11]}$

CONCLUSION: We encountered the twin problems of intraoperative anaphylactic reaction as well as acute hypernatremia postoperatively for having used $20 \%$ saline as scolicidal agent. Frequent and regular monitoring of intraoperative $\mathrm{Na}$, as well as early detection and treatment of anaphylaxis and hypernatremia were probably the determinant in the prognosis of this patient. Probably, cetrimide as a scolicidal agent may be a better choice so that the problem of hypernatremia can be avoided.

\section{REFERENCES:}

1. Marwah S, Subramanian P, Marwah N, Rattan KN, Karwasra RK. Infected Primary Intramuscular Echinococcosis of Thigh. Indian J Pediatr 2005; 72(9): 799-800.

2. Unusual Presentation of Hydatid Cyst: A Case Series with Review of Literature. Internet journal of parasitic disease 2013, Volume 6, Number 1.

3. H. Besim, K. Karayalin, O. Hamamci, Gongor and a. Korkmaz, Scolicidal agents in Hydatid Cyst Surgery, hpb surgery, 1998, vol. 10, pp. 347-51.

4. Mustapha Bensghir, Salaheddine Fjouji, Najib Bouhabba, Redouane Ahtil, Alain Traore, Hicham Azendour, and Nordine Drissi Kamili. Anaphylactic Shock during Hydatid Cyst Surgery. Saudi J Anaesth. 2012 Apr-Jun; 6(2): 161-4.

5. Hari Charan Perigela, M Koti Reddy, B Vara Prasad, J Narahari. Giant pelvic hydatid cyst. J NTR Univ Health Sci 2013; 2: 218-21.

6. Le Veen HH, LeVeen RF, Le Veen EG. The Mythology of Povidone-iodine and the Development of self-sterilizing plastics. Surg Gynecol Obstet 1993; 176: 183-90. 
7. Kloeck W, Cummins RO, Chamberlain D, Bossaert L, Callanan V, Carli P, et al. Special Resuscitation Situations: An advisory statement from the International Liaison Committee on Resuscitation. Circulation 1997; 95: 2196-210.

8. Graff J, Fugleberg S, Brahm J, Fogh Andersen N. Transperitoneal transport of sodium during hypertonic peritoneal dialysis. Clin Physiol 1996; 16: 31-9.

9. Gullans SR, Verbalis JG. Control of brain volume during hyperosmolar and hypoosmolar conditions. Annu Rev Med 1993; 44: 289-301.

10. Handy TC, Hanzlick R, Shields LB, et al. Hypernatremia and subdural hematoma in the pediatric age group: is there a causal relationship? J Forensic Sci1999; 44: 1114-8.

11. Ayus JC, Armstrong DL, Arieff AI. Effects of hypernatraemia in the central nervous system and its therapy in rats and rabbits. J Physiol 1996; 492: 243-55.

\section{AUTHORS:}

1. Anand Rampure Vittal Rao

2. Vijay Narayanan S.

3. Santhosh C. Gudimani

\section{PARTICULARS OF CONTRIBUTORS:}

1. Associate Professor, Department of Anaesthesiology and Critical Care, Saveetha Medical College.

2. Associate Professor, Department of Anaesthesiology and Critical Care, Saveetha Medical College.

FINANCIAL OR OTHER COMPETING INTERESTS: None
3. Associate Professor, Department of Surgery, Kannur Medical College.

\section{NAME ADDRESS EMAIL ID OF THE} CORRESPONDING AUTHOR:

Dr. Anand Rampure Vittal Rao, B2T1, VGN Minerva Guruswamy Road, Nolambur - 600095, Chennai.

E-mail: dranandrampure@gmail.com

Date of Submission: 17/04/2015.

Date of Peer Review: 18/04/2015.

Date of Acceptance: 30/04/2015.

Date of Publishing: 11/05/2015. 